\title{
Study of the Effect of Early Versus Delayed Enteral Nutrition in Critically Ill Mechanically Ventilated Medical Patients
}

\author{
MERVAT M. MARZOUK, M.D.; MANAL K. SHAMS, M.D.; DIAA ELDIN Sh. ELAWADY, M.D. and \\ AHMED A.H. ELSEDEK, M.Sc. \\ The Department of Anesthesia, Intensive Care and Pain Management, Faculty of Medicine, Ain Shams University
}

\begin{abstract}
Background: At the present time, the optimal timing and use of enteral nutrition for mechanically ventilated medical patients is unknown. The current study will focus on the effect of early versus delayed enteral nutrition in critically ill mechanically ventilated medical patients.
\end{abstract}

Aim of Study: To compare between early versus delayed enteral feeding in Invasive Mechanical Ventilation (IMV) patients. To assess association linking early nutrition $(<48$ hours after intubation), feeding route and calorie intake to mortality and risk of Ventilator Associated Pneumonia ( VAP) in patient with Invasive Mechanical Ventilation (IMV)

Patients and Methods: Patients will be scheduled to received their estimated total daily enteral nutritional requirements on either day 1 (early-feeding group) or day 5 (latefeeding group) of mechanical ventilation. Patients in the latefeeding group will be also scheduled to receive $20 \%$ of their estimated daily enteral nutritional requirements during the first 4 days of mechanical ventilation. Thirty (50\%) consecutive eligible patients will be entered into the early-feeding group and thirty $(50 \%)$ patients will be enrolled in the late-feeding group. All patients will be received enteral nutrition via continuous infusion by a feeding pump. Eligible patients will be followed in ICU for a maximum of 12 days or until deathor discharge from ICU.

Results: Logistic regression analysis shows that; after applying (forward method) and entering some predictor variables; the increase in BMI and late feeding technique; had an independent effect on increasing the probability of mortality occurrence; with significant statistical difference ( $p$ $<0.05$ respectively). The increase in BMI and late feeding technique; had an independent effect on increasing the probability of VAP occurrence; with significant statistical difference ( $p$ $<0.05$ respectively). By using ROC-curve analysis, early enteral feeding predicted shortening of hospital stay, with failed $(64 \%)$ accuracy, sensitivity $=63 \%$ and specificity $=63 \%(p$ $<0.05)$.

Conclusion: Evidence shows improvement in patient outcomes associated with the use of EEN in a diverse population of critically ill patients. The results of our study strengthen our understanding of the benefits of EEN. These Correspondence to: Dr. Ahmed A.H. Elsedek,E-Mail: ahmedsedek9999@gmail.com were evident even though $<50 \%$ of the patients in each group reached a goal rate of EN. Given the potential ease of consistent implementation of EEN, the minimal cost associated with such a practice, and the potentially substantial.

Key Words: Acute lung injury - Acute respiratory distress syndrome - Intensive care units.

\section{Introduction}

ACCORDING to different studies, one of the most important entities in Intensive Care Units (ICUs) is Acute Lung Injury (ALI) or Acute Respiratory Distress Syndrome (ARDS). In this subpopulation of patients, persistent hypoxemia may entail additional treatments, such as mechanical ventilation in the ICUs. Mechanical ventilation was, first recommended in 1976 can be readily implemented in any ICU and has been shown to improve respiratory mechanics and arterial oxygenation in patients with ARDS [1]. Patients admitted to ICUs who need MV are expected to have higher mortality rates compared with those who do not require respiratory support [2].

Critically ill patients are at particular risk of malnutrition, which occurs in up to $40 \%$ of the cases. The metabolic changes that occur in response to stress lead to an increase in protein catabolism, resulting in a significant loss of lean body mass, which in turn results in a higher incidence of complications, especially infectious ones, in an increase in wound dehiscence and in unfavorable outcomes [3]. Nutritional support in critically ill patients was considered as an adjunctive care to provide exogenous fuels to support the patient during the period of stress. This support had 3 main goals:

1- To preserve the lean body mass.

2- To maintain the immune function.

3- To avoid metabolic complications. 
Feeding an ICU patient now extends beyond choosing the right feeding route, the rate and the caloric density. In modern critical care, the concept of 'therapeutic nutrition' is replacing traditional ' supportive nutrition [4].

Enteral feeding is considered to be more costeffective than Total Parenteral Nutrition (TPN), but TPN remains a common therapeutic intervention in the ICU and represents a significant burden on health care budgets. Although it is generally accepted that early enteral nutrition is of benefit to critically ill patients, there is little conclusive evidence to support this assertion among medical or nonsurgical patients. Enteral alimentation is currently the most widely used modality for providing nutrition support in the ICU. However, infectious hazards, tissue injury, and aspiration associated with placement and maintenance of orogastric and nasogastric tubes used for the delivery of enteral nutrition suggest that not all patients benefit from this treatment [5].

At the present time, the optimal timing and use of enteral nutrition for mechanically ventilated medical patients is unknown [6]. Unnecessary enteral feeding potentially subjects patients to the risks of aspiration and nosocomial pneumonia, but the avoidance of enteral feeding may delay tissue and organ repair, resulting in prolonged hospitalization [7].

\section{Aim of the work:}

The present study aims to compare between early versus delayed enteral feeding in Invasive Mechanical Ventilation (IMV) patients. To assess association linking early nutrition $(<48$ hours after intubation), feeding route and calorie intake to mortality and risk of Ventilator Associated Pneumonia (VAP) in patient with Invasive Mechanical Ventilation (IMV).

\section{Patients and Methods}

Design: Prospective comparative study.

Setting: The present study will be carried out at General Intensive Care Unit (ICU), Ain Shams University Hospitals, Egypt.

Study period: From September 2019 to November 2019.

Patients: A total of 60 adult patients (older than 18 years old) intubated and mechanically ventilated within 48 hours of ICU admission, stayed in ICU for > 72 hours, will be enrolled in the study.
Eligible patients will be selected according to the following inclusion and exclusion criteria:

Inclusion criteria: Any adult patient with an age $>$ _18 years who is received IMV within 48 hours.

Exclusion criteria: Patients transferred to the medical ICU temporarily because of a lack of available beds in 1 of the other hospital ICUs. Patients who will be expected to die or be extubated within 24 hours of ICU admission; if they had received prior mechanical patients will be received prior mechanical ventilation during the same hospitalization. Contraindication to enteral feeding ( e.g.: Pancreatitis, short gut syndrome, or malabsorption syndrome). Surgical patients. Malnourished patients by the ICU.

\section{Methods:}

Eligible patients will be followed in ICU for a maximum of 12 days or until death or discharge from ICU.

All patients will be subjected to: Different laboratory parameters will be monitored to each patient on enteral nutrition daily until patient becomes stable, then 1-2 times/week. Labs these include: Renal function test and serum electrolytes. Blood glucose. Calcium and albumin. Magnesium and phosphorous.

The primary outcome measured will be the occurrence of Ventilator Associated Pneumonia ( VAP).

Secondary outcome measures will be included duration of mechanical ventilation, ICU and hospital lengths of stay (LOS), hospital mortality, diarrhea, and total number of antibiotic days in the ICU.

Ethical consideration: The study protocol will be approved by the Ethics Committee of Faculty of Medicine, Ain Shams University. Written informed consent will be obtained from all the participants.

\section{Statistical methodology: \\ Sample size justification:}

Using STATA program, version 10, setting alpha error at $5 \%$ and power at $90 \%$, results from a previous study Woo et al. [8] showed that pneumonia among early group was present in $5.5 \%$ of cases while among delayed group, it was present in $44 \%$ of cases. Based on these results, the needed sample will be 30 cases per group (total 60). Data entry, processing and statistical analysis was carried 
out using MedCalc ver. 18.2.1 (MedCalc, Ostend, Belgium). Tests of significance (Mann-Whitney's, Chi square, logistic regression analysis, Spearman's correlation, and ROC curve analysis) were used. Data were presented and suitable analysis was done according to the type of data (parametric and non-parametric) obtained for each variable. $p$ values less than $0.05(5 \%)$ was considered to be statistically significant.

$p$-value: Level of significance: $p>0.05$ : NonSignificant (NS). $p<0.05$ : Significant (S). $p<0.01$ : Highly Significant (HS).

\section{Descriptive statistics: Mean, Standard} Deviation $( \pm$ SD) and range for parametric numerical data, while median and Inter-Quartile Range (IQR) for non-parametric numerical data. Frequency and percentage of non-numerical data.

Analytical statistics: Mann-Whitney's Test (Utest) was used to assess the statistical significance of the difference of a non-parametric variable between two study groups. Chi-Square test was used to examine the relationship between two qualitative variables. Correlation analysis (using Spearman's method): To assess the strength of association between two quantitative variables. The correlation coefficient denoted symbolically $" r "$ defines the strength and direction of the linear relationship between two variables. Logistic regression: Useful in the prediction of the presence or absence of an outcome based on a set of independent variables. It is similar to a linear regression model but is suited when the dependent variable is qualitative (categorical). The ROC curve (receiver operating characteristic) provides a useful way to evaluate the sensitivity and specificity for quantitative diagnostic measures that categorize cases into one of two groups.

\section{Statistical analysis:}

Data entry, processing and statistical analysis was carried out using MedCalc ver. 18.2.1 (MedCalc, Ostend, Belgium). Tests of significance ( Mann-Whitney's, Chi square, logistic regression analysis, Spearman's correlation, and ROC curve analysis) were used. Data were presented and suitable analysis was done according to the type of data (parametric and non-parametric) obtained for each variable. $p$-values less than 0.05 (5\%) was considered to be statistically significant.

$p$-value: Level of significance: $p>0.05$ : NonSignificant (NS). $p<0.05$ : Significant (S). $p<0.01$ : Highly Significant (HS).
Descriptive statistics: Mean, standard deviation $( \pm$ SD) and range for parametric numerical data, while median and Inter-Quartile Range (IQR) for non-parametric numerical data. Frequency and percentage of non-numerical data.

Analytical statistics: Mann-Whitney's Test (Utest) was used to assess the statistical significance of the difference of a non-parametric variable between two study groups. Chi-square test was used to examine the relationship between two qualitative variables. Correlation analysis (using Spearman's method): To assess the strength of association between two quantitative variables. The correlation coefficient denoted symbolically $" r$ " defines the strength and direction of the linear relationship between two variables. Logistic regression: Useful in the prediction of the presence or absence of an outcome based on a set of independent variables. It is similar to a linear regression model but is suited when the dependent variable is qualitative (categorical). The ROC curve (receiver operating characteristic) provides a useful way to evaluate the sensitivity and specificity for quantitative diagnostic measures that categorize cases into one of two groups. Excellent accuracy $=0.90$ to $1(\%)$. Good accuracy $=0.80$ to $0.90(\%)$. Fair accuracy $=0.70$ to $0.80(\%)$. Poor accuracy $=0.60$ to $0.70(\%)$. Failed accuracy $=0.50$ to $0.60(\%)$.

\section{Results}

This was a prospective comparative study conducted on 60 adult patients (older than 18 years old) intubated and mechanically ventilated within 48 hours of ICU admission, stayed in ICU for $\geq 72$ hours will be enrolled in the study; to compare between early versus delayed enteral feeding in Invasive Mechanical Ventilation (IMV) patients. To assess association linking early nutrition $(<48$ hours after intubation), feeding route and calorie intake to mortality and risk of Ventilator Associated Pneumonia (VAP) in patient with Invasive Mechanical Ventilation (IMV) and shock.

Table (1): Socio-demographic data among 60 patients.

\begin{tabular}{ll}
\hline Variables & Frequency $(\%)$ \\
\hline Age (years) & $55.4 \pm 9.8 *$ \\
Gender: & \\
Female & $27(45 \%)$ \\
Male & $33(55 \%)$ \\
\hline *: Mean \pm SD.
\end{tabular}

This table shows that; the mean age of all patients was (55.4 \pm 9.8$)$ years. Regarding gender of the patients, the majority $(55 \%)$ of patients weremales; while $(45 \%)$ were females. 
Table (2): Basic clinical data among 60 patients.

\begin{tabular}{ll}
\hline Variables & Frequency $(\%)$ \\
\hline BMI & $29.8 \pm 6.5$ \\
HTN & $14(23.3 \%)$ \\
DM & $15(25 \%)$ \\
IHD & $9(15 \%)$ \\
Feeding route (Nasogastric tube) & $60(100 \%)$ \\
\hline
\end{tabular}

BMI : Body Mass Index. DM: Diabetes Mellitus.

HTN : Hypertension. IHD: Ischemic Heart Disease.

This table shows that; the mean BMI of all patients was (29.8 \pm 6.5$)$, with $(23.3 \%)$ had HTN, ( $25 \%$ ) had DM, and (15\%) had IHD. Regarding feeding route, all patients had nasogastric tube.

Table (3): Laboratory data among 60 patients.

\begin{tabular}{lll}
\hline Variables & Mean & SD \\
\hline Creat. (mg/dL) & 0.722. & 0.22 \\
Alb. (g/dL) & 75109. & 0.73 \\
FBS (mg/dL) & 08 & 15.54 \\
$\mathrm{Ca}(\mathrm{mg} / \mathrm{dL})$ & 9.3 & 1.04 \\
$\mathrm{Mg}(\mathrm{mEq} / \mathrm{dL})$ & 1.87 & 0.19 \\
$\mathrm{Ph}(\mathrm{mEq} / \mathrm{dL})$ & 3.86 & 0.53 \\
\hline Alb : Albumin. & $\mathrm{Ca}:$ Calcium. \\
Creat. : Creatinine. & $\mathrm{Mg}$ : Magnesium. \\
FBS : Fasting Blood Sugar. & $\mathrm{Ph}$ : Phosphorus.
\end{tabular}

This table shows that; the mean value of each baseline laboratory variable.

Table (4): Outcome data among 60 patients.

\begin{tabular}{lc}
\hline Variables & Frequency $(\%)$ \\
\hline Total number of antibiotic days & $10.3 \pm 2.4$ \\
Hospital stay (days) & $16.1 \pm 5.3$ \\
ICU stay (days) & $6.7 \pm 3.9$ \\
Diarrhea: +ve & $8(13.3 \%)$ \\
VAP: +ve & $11(18.3 \%)$ \\
Mortality rate: +ve & $10(16.7 \%)$
\end{tabular}

VAP: ventilator associated pneumonia. ICU: Intensive Care Unit.

Regarding outcome data, (13.3\%) of patients had diarrhea, (18.3\%) had VAP, and (16.7\%) suffered mortality. The average antibiotic days was ( $10.3 \pm 2.4$ ) days, the average hospital stay was ( $16.1 \pm 5.3$ ) days, and the average ICU stay was ( $6.7 \pm 3.9)$ days.

Table (5): Comparison between the 2 groups as regards sociodemographic data using Mann-Whitney's U and Chi square tests.

\begin{tabular}{lccc} 
Variable & $\begin{array}{c}\text { Early feeding } \\
\text { group (30) } \\
\text { Median (IQR) }\end{array}$ & $\begin{array}{c}\text { Late feeding } \\
\text { group (30) } \\
\text { Median (IQR) }\end{array}$ & $\begin{array}{c}\text { Mann-Whitney's } \\
\text { U-test } \\
p \text {-value }\end{array}$ \\
\hline Age (years) & $52.5(45-63)$ & $57.5(47-66)$ & $=0.5197$ \\
\hline Variable & $\begin{array}{c}\text { Early feeding } \\
\text { group (30) }\end{array}$ & $\begin{array}{c}\text { Late feeding } \\
\text { group (30) }\end{array}$ & $\begin{array}{c}\text { Chi square test } \\
p \text {-value }\end{array}$ \\
\hline $\begin{array}{l}\text { Gender: } \\
\text { Female } \\
\text { Male }\end{array}$ & $12(40 \%)$ & $15(50 \%)$ & $=0.4401$ \\
& $18(60 \%)$ & $15(50 \%)$ &
\end{tabular}

IQR: Inter-Quartile Range. $\quad *$ : Percentage of column total.
Comparative study between the 2 groups revealed non-significant difference as regards age and sex of the patients $(p>0.05)$.

Table (6): Comparison between the 2 groups as regards basic clinical data using Mann-Whitney's U and Chi square tests.

\begin{tabular}{|c|c|c|c|}
\hline Variable & $\begin{array}{l}\text { Early feeding } \\
\text { group (30) } \\
\text { Median (IQR) }\end{array}$ & $\begin{array}{l}\text { Late feeding } \\
\text { group (30) } \\
\text { Median (IQR) }\end{array}$ & $\begin{array}{c}\text { Mann-Whitney's } \\
\text { U-test } \\
p \text {-value }\end{array}$ \\
\hline BMI & $26.7(23.8-32.9)$ & $31.8(25.9-35.3)$ & $=0.1392$ \\
\hline Variable & $\begin{array}{l}\text { Early feeding } \\
\text { group (30) }\end{array}$ & $\begin{array}{l}\text { Late feeding } \\
\text { group (30) }\end{array}$ & $\begin{array}{c}\text { Chi square test } \\
p \text {-value }\end{array}$ \\
\hline HTN: +ve & $8(26.7 \%)$ & $6(20 \%) 6$ & $=0.5449$ \\
\hline DM: +ve & $9(30 \%)$ & $(20 \%) 5($ & $=0.3751$ \\
\hline IHD: +ve & $4(13.3 \%)$ & $16.7 \%)$ & $=0.7200$ \\
\hline
\end{tabular}

*: Percentage of column total.

Comparative study between the 2 groups revealed non-significant difference as regards all basic clinical data $(p>0.05)$.

Table (7): Comparison between the 2 groups as regards laboratory data using Mann-Whitney's U-test.

\begin{tabular}{lllc}
\hline Variable & $\begin{array}{c}\text { Early feeding } \\
\text { group (30) } \\
\text { Median (IQR) }\end{array}$ & $\begin{array}{c}\text { Late feeding } \\
\text { group (30) } \\
\text { Median (IQR) }\end{array}$ & $\begin{array}{c}\text { Mann-Whitney's } \\
\text { U-test } \\
\text {-value }\end{array}$ \\
\hline Creat. (mg/dL) & $0.7(0.6-0.8)$ & $0.7(0.6-1)$ & $=0.8401$ \\
Alb. (g/dL) & $2.75(2-3.3)$ & $2.7(2.3-3.2)$ & $=0.9881$ \\
FBS (mg/dL) & $106.5(96-119)$ & $107.5(100-114)$ & $=0.7503$ \\
$\mathrm{Ca}(\mathrm{mg} / \mathrm{dL})$ & $9.5(8.5-10.2)$ & $9.4(8.7-9.9)$ & $=0.6894$ \\
$\mathrm{Mg}(\mathrm{mEq} / \mathrm{dL})$ & $1.9(1.7-2.1)$ & $1.8(1.7-2)$ & $=0.6695$ \\
$\mathrm{Ph}(\mathrm{mEq} / \mathrm{dL})$ & $3.9(3.5-4.1)$ & $3.8(3.4-4.3)$ & $=0.8997$ \\
\end{tabular}

Comparative study between the 2 groups revealed non-significant difference as regards all baseline laboratory data $(p>0.05)$.

Table (8): Comparison between the 2 groups as regards outcome data using Mann-Whitney's U and Chi square tests.

\begin{tabular}{|c|c|c|c|}
\hline Variable & $\begin{array}{l}\text { Early feeding } \\
\text { group (30) } \\
\text { Median (IQR) }\end{array}$ & $\begin{array}{l}\text { Late feeding } \\
\text { group (30) } \\
\text { Median (IQR) }\end{array}$ & $\begin{array}{c}\text { Mann-Whitney's } \\
\text { U-test } \\
p \text {-value }\end{array}$ \\
\hline $\begin{array}{l}\text { - Total number of } \\
\text { antibiotic days }\end{array}$ & $10(7-12)$ & $10(8-13)$ & $=0.2382$ \\
\hline $\begin{array}{l}\text { - Hospital stay( } \\
\text { days) }\end{array}$ & $15(9-19)$ & $17(14-22)$ & $=0.0559$ \\
\hline - ICU stay (days) & $(3-5)$ & $7.5(5-11)$ & $=0.000048 * *$ \\
\hline Variable & $\begin{array}{l}\text { Early feeding } \\
\text { group (30) }\end{array}$ & $\begin{array}{l}\text { Late feeding } \\
\text { group (30) }\end{array}$ & $\begin{array}{c}\text { Chi square test } \\
p \text {-value }\end{array}$ \\
\hline Diarrhea: +ve & $5(16.7 \%)$ & $3(10 \%)$ & $=0.4513$ \\
\hline VAP: +ve & $2(6.7 \%)$ & $9(30 \%)$ & $=0.02 *$ \\
\hline Mortality rate: +ve & $2(6.7 \%)$ & $8(26.7 \%)$ & $=0.039 *$ \\
\hline
\end{tabular}

*: Percentage of column total.

Comparative study between the 2 groups revealed; highly significant decrease in ICU stay in early feeding group; compared to late feeding 
group; with highly significant statistical difference ( $p$ $<0.01$ ). Comparative study between the 2 groups revealed; significant decrease in VAP and mortality in early feeding group; compared to late feeding group; with significant statistical difference $(p<0.05$ respectively). Comparative study between the 2 groups revealed non-significant difference as regards antibiotic days, hospital stay and diarrhea ( $p$ $>0.05$ ).

Table (9): Spearman's correlation analysis for baseline clinical/ laboratory factors associated with ICU stay.

\begin{tabular}{lll}
\hline \multirow{2}{*}{ Associated factor } & \multicolumn{2}{c}{ ICU stay } \\
\cline { 2 - 3 } & \multicolumn{2}{c}{ rho } \\
\hline Age (years) & -0.156 & $=0.2333$ \\
BMI & 0.379 & $=0.0028 * *$ \\
Creat. (mg/dL) & -0.0511 & $=0.6980$ \\
Alb. (g/dL) & -0.0990 & $=0.4517$ \\
FBS (mg/dL) & -0.0422 & $=0.7491$ \\
Ca (mg/dL) & -0.0378 & $=0.7742$ \\
Mg (mEq/dL) & 0.191 & $=0.1435$ \\
Ph (mEq/dL) & -0.0978 & $=0.4574$ \\
\hline
\end{tabular}

rho: Spearman's rho (correlation coefficient).

Spearman's correlation analysis shows that; BMI had a highly significant positive correlation with ICU stay; with highly significant statistical difference $(p=0.0028)$.

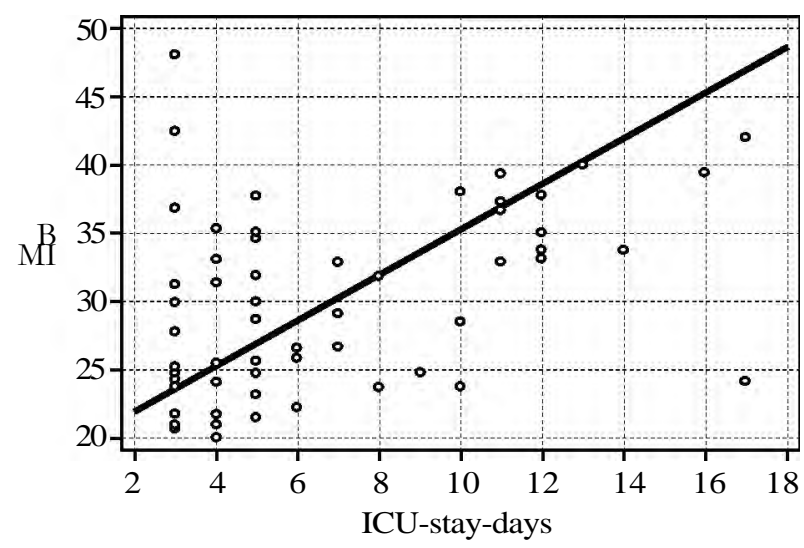

Fig. (1): Correlation between ICU stay and BMI.

Table (10): Logistic regression model for the factors affecting mortality occurrence using forward method.

\begin{tabular}{lrrl}
\hline Predictor factor & Coefficient & OR & $p$-value \\
\hline (Constant) & -5.78462 & & \\
BMI & 0.14895 & 1.1606 & $0.018^{*}$ \\
Late feeding & 1.64833 & 1.1924 & $0.007^{* *}$ \\
\hline
\end{tabular}

Other factors excluded from the model as ( $p$-value $>0.1)$.

OR: Odds Ratio.

Logistic regression analysis shows that; after applying (forward method) and entering some predictor variables; the increase in BMI and late feeding technique; had an independent effect on increasing the probability of mortality occurrence; with significant statistical difference $(p<0.05$ respectively).

Table (11): Logistic regression model for the factors affecting VAP occurrence using forward method.

\begin{tabular}{llll}
\hline Predictor factor & Coefficient & OR & $p$-value \\
\hline (Constant) & -6.16314 & & \\
BMI & 0.16619 & 1.1808 & $0.0099^{* *}$ \\
Late feeding & 1.88660 & 1.1516 & $0.042^{*}$ \\
\hline
\end{tabular}

Other factors excluded from the model as ( $p$-value $>0.1$ ). OR: Odds Ratio.

Logistic regression analysis shows that; after applying (forward method) and entering some predictor variables; the increase in BMI and late feeding technique; had an independent effect on increasing the probability of VAP occurrence; with significant statistical difference ( $p<0.05$ respectively).

Table (12): Roc-curve of early enteral feeding to predict patients' stay outcomes.

\begin{tabular}{lllllll}
\hline Variable & AUC & SE & $\begin{array}{l}\text { Criterion } \\
\text { "Cut off }\end{array}$ & \multicolumn{3}{l}{ SensiSpeci- } \\
& & & point" & $(\%)$ & $(\%)$ & \\
\hline Antibiotic days & 0.588 & 0.0739 & 57 & 30 & 93.33 & 0.2350 \\
Hospital stay & 0.643 & 0.0713 & 516 & 63.33 & 63.33 & $0.044^{*}$ \\
ICU stay & 0.802 & 0.0573 & 54 & 63.33 & 86.67 & $<0.0001^{* *}$ \\
\hline
\end{tabular}

ROC: Receiver Operating Characteristic.

AUC: Area Under Curve. $\quad$ SE: Standard Error.

By using ROC-curve analysis, early enteral feeding predicted shortening of ICU stay, with good $(80 \%)$ accuracy, sensitivity $=63 \%$ and specificity $=87 \%(p<0.01)$. By using ROC-curve analysis, early enteral feeding predicted shortening of hospital stay, with failed (64\%) accuracy, sensitivity= $63 \%$ and specificity $=63 \%(p<0.05)$. By using ROCcurve analysis, early enteral feeding showed nonsignificant predictive values in shortening antibiotic days $(p>0.05)$.

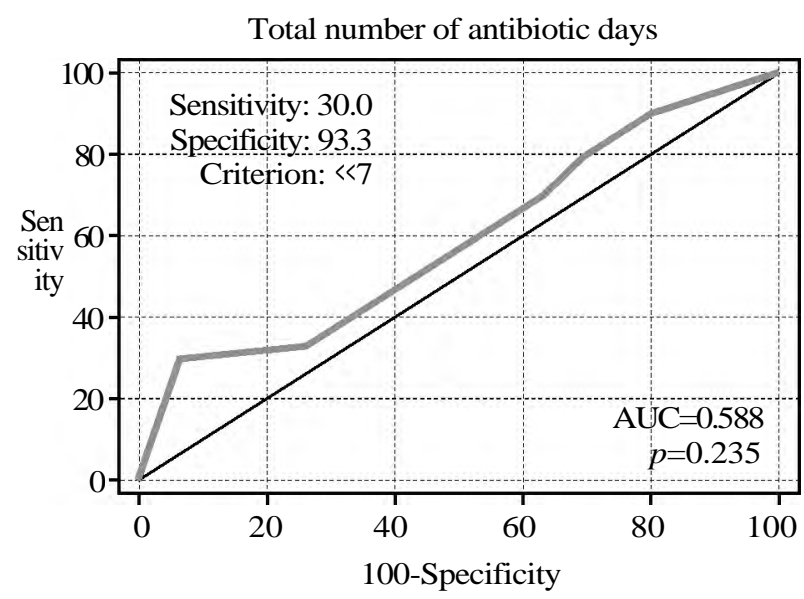

Fig. (2): ROC curve of early enteral feeding (antibiotic days). 
Hospital stay days

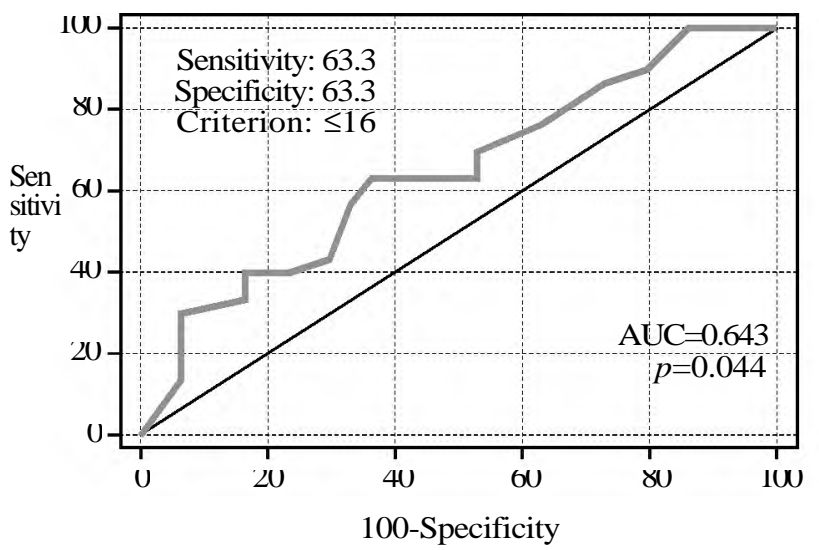

Fig. (3): ROC curve of early enteral feeding (hospital stay).

\section{Discussion}

This was a prospective comparative study conducted on 60 adult patients (older than 18 years old) intubated and mechanically ventilated within 48 hours of ICU admission, stayed in ICU for $\geq 72$ hours will be enrolled in the study; to compare between early versus delayed enteral feeding in Invasive Mechanical Ventilation (IMV) patients. To assess association linking early nutrition $(<48$ hours after intubation), feeding route and calorie intake to mortality and risk of Ventilator Associated Pneumonia (VAP) in patient with Invasive Mechanical Ventilation (IMV) and shock.

Patients will be scheduled to received their estimated total daily enteral nutritional requirements on either day 1 (early-feeding group) or day 5 ( late-feeding group) of mechanical ventilation. Patients in the late-feeding group will be also scheduled to receive $20 \%$ of their estimated daily enteral nutritional requirements during the first 4 days of mechanical ventilation. Thirty $(50 \%)$ consecutive eligible patients will be entered into the early-feeding group and thirty (50\%) patients will be enrolled in the late-feeding group. All patients will be received enteral nutrition via continuous infusion by a feeding pump.

Eligible patients will be followed in ICU for a maximum of 12 days or until death or discharge from ICU.

The primary outcome measured will be the occurrence of ventilator-associated pneumonia. Secondary outcome measures will be included duration of mechanical ventilation, ICU and hospital Lengths of Stay (LOS), hospital mortality, diarrhea, and total number of antibiotic days in the ICU.

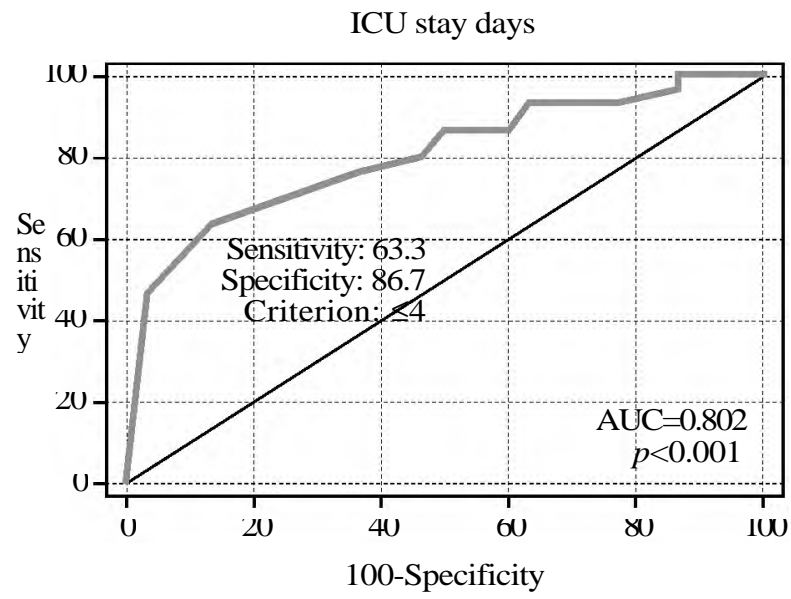

Fig. (4): ROC curve of early enteral feeding (short ICU stay).

Different laboratory parameters will be monitored to each patient on enteral nutrition daily until patient becomes stable, then 1-2 times/week. These include:

Renal function test and serum electrolytes, blood glucose, Calcium, albumin, Magnesium and phosphorous.

We found that; the mean age of all patients was ( $55.4 \pm 9.8)$ years. Regarding gender of the patients, the majority $(55 \%)$ of patients were males; while ( $45 \%$ ) were females, which came in agreement with Mok et al. [9], Mosier et al. [10], Nguyen et al. [11], Poulard et al. [12], WereszczynskaSiemiatkowska et al. [13] and Woo et al. [8].

Mok et al., reported that, the early group and delayed group were similar in age (median 62.0 years vs. 64.2 years; $p=0.17$ ) and sex (males $64.6 \%$ vs. $63.4 \%$; $p=0.91$ ) [9].

Mosier et al., reported that, eligible subjects included all mechanically ventilated adults with complete outcome data enrolled in the burn arm of the "inflammation and host response to injury" program from March 2004 to September 2009, with age was 41 [15] in all groups [10].

Nguyen et al., reported that, the demographics, disease severity, admission diagnosis, and the use of medications that potentially affect gastrointestinal function were comparable between patients who received early and delayed feeding. The age was $54.9 \pm 3.3$ in early feeding group and was 56 . $3 \pm 3.4$ in delayed group [11].

Poulard et al., reported that, this prospective before-after study was performed from July 2004 to July 2006 in the 15-bed adult medical-surgical Intensive Care Unit (ICU) of the District Hospital 
Center in La Roche-sur-Yon, France. The age was $62 \pm 16[12]$.

Wereszczynska-Siemiatkowska et al., reported that, of the 420 patients with AP, 197 patients ( 47\%) met the inclusion and exclusion criteria and were considered for the final analysis. Of the 197 patients with severe AP, 97 patients (49\%) were allocated to group A ("early" EN) and 100 patients ( $51 \%$ ) were allocated to group B ("delayed" EN). The age was 49 (39-56) [13].

Woo et al., reported that, throughout the study timeframe, 146 patients were evaluated for inclusion. Of the 146 patients, 110 patients met 1 or more exclusion criteria, leaving 36 patients eligible for inclusion. The age was $66.1 \pm 17.1$ in early group and was 60.4 \pm 15.6 in delayed group [8].

We found that; the mean BMI of all patients was $(29.8 \pm 6.5)$, with $(23.3 \%)$ had HTN, $(25 \%)$ had DM, and (15\%) had IHD. Which came in agreement with Yin et al. [14], Woo et al. [8], Nguyen et al. [11] and Chouillard et al. [15].

Yin et al., reported that, of the 88 patients, 28 ( $31.8 \%$ ) received early enteral feeding within 72 $\mathrm{h}$ of SICU admission. These patients were allocated to the early-initiation group, whereas the remaining 60 patients who received enteral feeding after $72 \mathrm{~h}$ of admission were allocated to the delayed-initiation group. BMI $\left(\mathrm{kg} / \mathrm{m}^{2}\right)$, mean \pm SD was $22.1 \pm 2.4$ in early group and $22.7 \pm 2.2$ in delayed group with $p=.022$ [14].

Woo et al., reported that, 146 patients were evaluated for inclusion. Of the 146 patients, 110 patients met 1 or more exclusion criteria, leaving 36 patients eligible for inclusion, with mean BMI, $\mathrm{kg} / \mathrm{m}^{2}$ was $29.4 \pm 13.9$ in early group and was 26.3 \pm 6.8 in delayed one [8].

Nguyen et al., reported that, the demographics, disease severity, admission diagnosis, and the use of medications that potentially affect gastrointestinal function were comparable between patients who received early and delayed feeding. Body mass index $\left(\mathrm{kg} / \mathrm{m}^{2}\right) 28.3 \pm 1.7$ in early group and $27.4 \pm 1.9$ in delayed group [11].

Chouillard et al., reported that, fifty-nine patients admitted to the ICU were included in the study. The flow diagram presents enrollment, allocation, losses to follow-up, and number of patients per treatment group. BMI, $\mathrm{kg} / \mathrm{m}^{2}$, mean \pm SD was $25.18 \pm 1.97$ in delayed group and $24.86 \pm 2.06$ in early group [15].
Regarding outcome data, (13.3\%) of patients had diarrhea, (18.3\%) had VAP, and (16.7\%) suffered mortality. Which came in agreement with Mok et al. [9] and Woo et al. [8].

Mok et al., reported that, both groups spent a median of 5 calendar days (whole and part calendar days) in intensive care $(p=0.88)$. Intensive care mortality was $13.1 \%$ in the early group and $15.4 \%$ in the late group $(p=0.65)$ [9].

Woo et al., reported that, 4 patients in the early group and 2 patients in the delayed group experienced diarrhea during the ICU admission [8].

The average antibiotic days was $(10.3 \pm 2.4)$ days, the average hospital stay was $(16.1 \pm 5.3)$ days, and the average ICU stay was (6.7 \pm 3.9$)$ days, which came in agreement with Poulard et al. [12], Wereszczynska-Siemiatkowska et al. [13].

Poulard et al., reported that, the mean cumulative erythromycin dose over the 7-day study period was higher in the control group $(1593 \pm 1775 \mathrm{mg})$ than in the intervention group $(888 \pm 1515 \mathrm{mg})(p$ $<.05)[12]$.

Wereszczynska-Siemiatkowska et al., reported that, of the 420 patients with AP, 197 patients ( 47\%) met the inclusion and exclusion criteria and were considered for the final analysis. Of the 197 patients with severe AP, 97 patients (49\%) were allocated to group A ("early" EN) and 100 patients ( $51 \%$ ) were allocated to group B ("delayed" EN). Antibiotic prophylaxis, n (\%) was 84 (87) in delayed group and 94 (94) in early one with $p=0.078$ [13].

Woo et al., reported that, median hospital stay appeared shorter in the EEN group (10.4 days) compared with the delayed group (16.9 days) [8].

Comparative study between the 2 groups revealed non-significant difference as regards age and sex of the patients $(p>0.05)$, which came in agreement with Poulard et al. [12].

Poulard et al., reported that, age, sex, McCabe score, weight, SAPS II, SOFA score, admission diagnosis, and risk factors for enteral feeding intolerance did not differ between the 2 groups [12].

Comparative study between the 2 groups revealed non-significant difference as regards all basic clinical data $(p>0.05)$, which came in agreement with Wereszczynska-Siemiatkowska et al., [ 13], Woo et al., [8] and Mok et al., [9]. 
Wereszczynska-Siemiatkowska et al., reported that, there were no differences between the study groups in the BISAP score, the Ranson score, the Panc 3 score, the APACHE II score, and the SOFA score on day 1 . In both groups, a gradual decrease in APACHE II scores over the study days was observed, with no significant difference between groups A and B on any of the measured days [13].

Woo et al., reported that, there were no significant differences in the baseline characteristics of the 36 included patients [8].

Mok et al., reported that, there were no statistically significant differences between the groups in intensive care diagnosis (categorized by organ system and surgical status), there was a weak trend toward fewer cardiovascular non-surgical diagnoses in the early group (10.9\% vs. $17.1 \% ; p$ $=0.12$ ) [9].

Comparative study between the 2 groups revealed; significant decrease in VAP and mortality in early feeding group; compared to late feeding group; with significant statistical difference $(p<0.05$ respectively), which came in agreement with Tian et al. [16], Mosier et al. [10] and WereszczynskaSiemiatkowska et al., [13].

Tian et al., reported that, analysis within subgroups revealed that early EN reduced pneumonia compared with delayed enteral intake (OR, 0.27; 95\% CI, 0.10-0.70; $p=0.0071 ; \mathrm{I}^{2}=0 \%$ ), and there was a strong trend toward a reduction in pneumonia when early EN was compared with PN (OR, 0.80; 95\% CI, 0.63-1.00; $p=0.052$ ) [16].

Mosier et al., reported that, they evaluated the influence of early EN on time to ventilatorassociated pneumonia development and found that early EN was not a significant predictor (adjusted Hazard Ratio $[\mathrm{HR}]=1.23, p=.41,95 \%$ Confidence Interval [CI] 0.74-2.04) [10].

Wereszczynska-Siemiatkowska et al., reported that, overall, pulmonary complications occurred in 91 patients $(46.2 \%)$ : 42 patients $(43.3 \%)$ in group A and 49 patients in group B (49\%) [13].

Our result came in disagreement with Yin et al., [14].

Yin et al., reported that, there were no differences in the incidence of pneumonia, intraabdominal abscess, wound infection, and bacteremia between the two groups [14].

Comparative study between the 2 groups revealed non-cionificant difference ac reoards anti biotic days, hospital stay and diarrhea ( $p>0.05)$, which came in agreement with Poulard et al., [12].

Poulard et al., reported that, no differences found regarding mean duration of mechanical ventilation $(13 \pm 9$ vs. $14 \pm 12$ days, respectively; $p=.65)$, mean length of stay in the ICU ( $18 \pm 14$ vs. $17 \pm 15$ days; $p=.59)$, mean length of stay in hospital ( $27 \pm 22$ vs. $27 \pm 22$ days; $p=.98)$, ICU mortality $(24.5 \%$ vs. $35 \%$; $p=.13)$, or hospital mortality (35.3\% vs. $42.7 \%$; $p=.32)$ [12].

Logistic regression analysis shows that; after applying (forward method) and entering some predictor variables; the increase in BMI and late feeding technique; had an independent effect on increasing the probability of mortality occurrence; with significant statistical difference $(p<0.05$ respectively), which came in agreement with Woo et al., [8], Tian et al., [16] and Koretz and Lipman, [ 17].

Woo et al., reported that, total hospital mortality was higher in those patients who received delayed vs. EEN [8].

Tian et al., reported that, Analysis within subgroups revealed that early EN reduced mortality compared with delayed enteral intake (OR, $0.45 ; p$ $=0.038 ; \mathrm{I}^{2}=0 \%$, whereas a mortality difference was not detected when early EN was compared with PN (OR, 1.04; $\left.p=0.58 ; \mathrm{I}^{2}=30 \%\right)$ [16].

Koretz and Lipman reported that, when all trials were combined with meta-analysis, early enteral nutrition had a favorable effect on mortality (RR 0. $61,95 \%$ CI $0.41,0.89)$ and infectious morbidity ( RR 0.80 , 95\% CI $0.72,0.89$ ), but not on noninfectious morbidity or any secondary outcome [17].

Logistic regression analysis shows that; after applying (forward method) and entering some predictor variables; the increase in BMI and late feeding technique; had an independent effect on increasing the probability of VAP occurrence; with significant statistical difference $(p<0.05$ respectively), which came in agreement with Nguyen et al., [ 11], Woo et al., [8], Tian et al., [16] and Heighes et al., [18].

Nguyen et al., reported that, there were fewer ventilator-free days in the delayed feeding groups as compared to the early feeding groups (15.60 \pm 1.6 days vs. $20.30 \pm 1.1$ days; $p=.03$ ). Although the number of patients $(n=6)$ who had ventilatorassociated pneumonia in the delayed feeding group was twice the number of patients who received 
early feeding $(n=3)$, the difference did not reach statistical significance $(p=.22)$ [11].

Woo et al., reported that, incidence of new pneumonia was significantly higher in the delayed group compared with the EEN group (44\% vs. $55.5 \%, p=.02)[8]$.

Tian et al., reported that, analysis within subgroups revealed that early EN reduced pneumonia compared with delayed enteral intake (OR, 0.27; 95\% CI, 0.10-0.70; $p=0.0071 ; \mathrm{I}^{2}=0 \%$ ), and there was a strong trend toward a reduction in pneumonia when early EN was compared with PN (OR, 0.80; 95\% CI, 0.63-1.00; $p=0.052$ ) [16].

Heighes et al., reported that, in elective intestinal surgery, meta-analysis demonstrated a statistically significant reduction in mortality associated with early EN (Relative Risk [RR] 0.41, 95\% Confidence Interval [CI] 0.18 to $0.93, p=0.03, \mathrm{I}^{2}=0.0 \%$ ) [18].

By using ROC-curve analysis, early enteral feeding predicted shortening of ICU stay, with good $(80 \%)$ accuracy, sensitivity $=63 \%$ and specificity $=87 \% \quad(p<0.01)$, which came in agreement with Heighes et al., [18].

Heighes et al., reported that, two systematic reviews reported a reduction in length of stay associated with early EN: Elective intestinal surgery ( length of stay weighted mean difference -0.60 days, $95 \% \mathrm{CI}-0.66$ to -0.54 , heterogeneity $p=0.09$ ) and acutely ill hospitalized patients (length of stay weighted mean difference -2.2 days, $95 \%$ CI -3.63 to $-0.81, p=0.004$, heterogeneity $p=0.0012$ [18].

\section{Conclusion:}

Evidence shows improvement in patient outcomes associated with the use of EEN in a diverse population of critically ill patients. The results of our study strengthen our understanding of the benefits of EEN. These benefits were evident even though $<50 \%$ of the patients in each group reached a goal rate of EN. Given the potential ease of consistent implementation of EEN, the minimal cost associated with such a practice, and the potentially substantial.

\section{References}

1-GU W.J., WAN Y.D., TIE H.T., KAN Q.C. and SUN T.W.: Risk of acute lung injury/acute respiratory distress syndrome in critically ill adult patients with pre-existing diabetes: A meta-analysis. PloS one, 9 (2): e90426, 2014.

2- FIALKOW L., FARENZENA M., WAWRZENIAK I.C., BRAUNER J.S., VIEIRA S.R., VIGO A. and BOZZETTI M.C.: Mechanical ventilation in patients in the intensive care unit of a general university hospital in southern
Brazil: An epidemiological study. Clinics, 71 (3): 144$51,2016$.

3- SERON-ARBELOA C., ZAMORA-ELSON M., LABARTAMONZON L. and MALLOR-BONET T.: Enteral nutrition in critical care. Journal of Clinical Medicine Research, 5 (1): 1, 2013.

4- SHARADA M. and VADIVELAN M.: Nutrition in critically ill patients. Journal, Indian Academy of Clinical Medicine, 15 (3): 205-9, 2014.

5- KOZENIECKI M., McANDREW N. and PATEL J.J.: Process-related barriers to optimizing enteral nutrition in a tertiary medical intensive care unit. Nutrition in Clinical Practice, 31 (1): 80-5, 2016.

6- FREMONT R.D. and RICE T.W.: How soon should we start interventional feeding in the ICU? Current opinion in Gastroenterology, 30 (2): 178, 2014.

7- PADAR M., UUSVEL G., STARKOPF L., STARKOPF J. and BLASER A.R.: Implementation of enteral feeding protocol in an intensive care unit: Before-and-after study. World Journal of Critical Care Medicine, 6 (1): 56, 2017.

8- WOO S.H., FINCH C.K., BROYLES J.E., WAN J., BOSWELL R. and HURDLE A.: Early vs delayed enteral nutrition in critically ill medical patients. Nutrition in Clinical Practice, 25 (2): 205-11, 2010.

9- MOK K., SMITH R.J., REID D.A. and SANTAMARIA J.D. : Changing clinical guidelines from delayed to early aperient administration for enterally fed intensive care patients was associated with increased diarrhoea: A beforeand-after, intention-to-treat evaluation. Australian Critical Care, 28 (4): 208-13, 2015.

10- MOSIER M.J., PHAM T.N., KLEIN M.B., GIBRAN N.S., ARNOLDO B.D., GAMELLI R.L., TOMPKINS R.G. and HERNDON D.N.: Early enteral nutrition in burns: Compliance with guidelines and associated outcomes in a multicenter study. Journal of Burn Care \& Research, 32 (1): 104-9, 2011.

11- NGUYEN N.Q., BESANKO L.K., BURGSTAD C., BELLON M., HOLLOWAY R.H., CHAPMAN M., HOROWITZ M. and FRASER R.J.: Delayed enteral feeding impairs intestinal carbohydrate absorption in critically ill patients. Critical Care Medicine, 40 (1): 50-4, 2012.

12- POULARD F., DIMET J., MARTIN-LEFEVRE L., BONTEMPS F., FIANCETTE M., CLEMENTI E., LEBERT C., RENARD B. and REIGNIER J.: Impact of not measuring residual gastric volume in mechanically ventilated patients receiving early enteral feeding: A prospective before-after study. Journal of Parenteral and Enteral Nutrition, 34 (2): 125-30, 2010.

13- WERESZCZYNSKA-SIEMIATKOWSKA U., SWIDNICKA-SIERGIEJKO A., SIEMIATKOWSKI A. and DABROWSKI A.: Early enteral nutrition is superior to delayed enteral nutrition for the prevention of infected necrosis and mortality in acute pancreatitis. Pancreas, 42 (4): 640-6, 2013.

14- YIN J., WANG J., ZHANG S., YAO D., MAO Q., KONG W., REN L., LI Y. and LI J.: Early versus delayed enteral

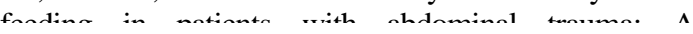


cohort study. European Journal of Trauma and Emergency Surgery, 41 (1): 99-105, 2015.

15- CHOUILLARD E., SCHOUCAIR N., ALSABAH S., ALKANDARI B., MONTANA L., DEJONGHE B. and BIAGINI J.: Laparoscopic gastric plication (LGP) as an alternative to laparoscopic sleeve gastrectomy (LSG) in patients with morbid obesity: A preliminary, short-term, case-control study. Obesity Surgery, 26 (6): 1167-72, 2016.

16- TIAN F., HEIGHES P.T., ALLINGSTRUP M.J. and DOIG
G.S.: Early enteral nutrition provided within 24 hours of ICU admission: A meta-analysis of randomized controlled trials. Critical Care Medicine, 46 (7): 1049-56, 2018.

17- KORETZ R.L. and LIPMAN T.O.: The presence and effect of bias in trials of early enteral nutrition in critical care. Clinical Nutrition, 33 (2): 240-5, 2014.

18- HEIGHES P.T., DOIG G.S., SWEETMAN E.A. and SIMPSON F.: An overview of evidence from systematic reviews evaluating early enteral nutrition in critically ill patients: More convincing evidence is needed. Anaesthesia and Intensive Care, 38 (1): 167-74, 2010.

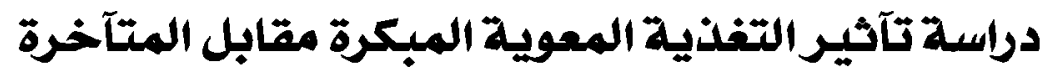

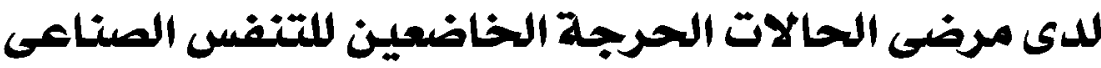

الهدف من الدراسة: دراسة تآثير التخذية المعوية المبكرة مقابل المتآخرة لدى مرضى الحالات الحرجة الخاضعين للتفس الصناعى.

المرضى وطرق العلاج: سيتم جلولة المرضى لتلى إجمالى الإحتياجات الغذائية المعوية اليومية المقدرة فى اليوم الآول (مجموعة التفذية

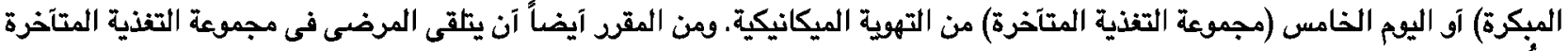

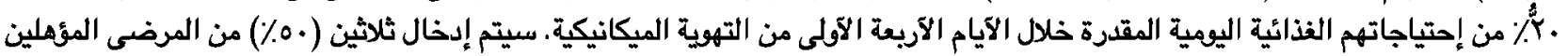

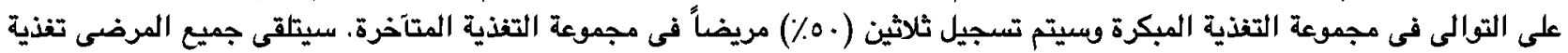

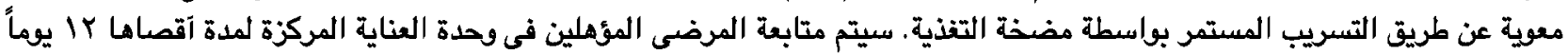
آو حتى الوفاة آو الخرج من من وحدة العناية المركزة. النتائج:علم وجول فروق ذات إحصائية فيما يتعلق بعمر وجنس المرضى، علم وجود فروق ذات دلالة إحصائية فيما يتعلق بجميع البيانات

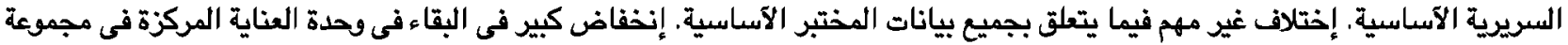

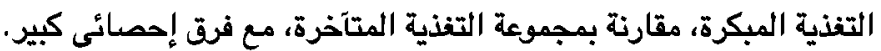

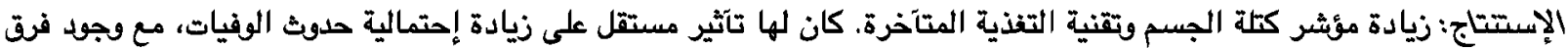

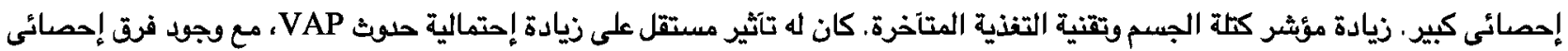

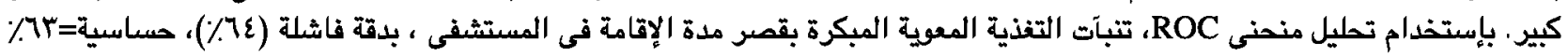

